\section{Growth of Immature Peach Embryos in Response to Media, Ovule Support Method, and Ovule Perforation}

\author{
Alberto C.Q. Pinto ${ }^{1}$, Suzanne M. Dethier Rogers ${ }^{2}$, and David H. Byrne ${ }^{3}$ \\ Department of Horticultural Sciences, Texas A\&MUniversity, College Station, \\ TX 77843-2133 \\ Additional index words. embryo culture, embryo rescue, nurse culture, ovule culture, peach \\ tissue culture, Prunus persica
}

\begin{abstract}
The influence of medium formulation, methods of ovule support, and ovule perforation on in vitro growth of immature peach [Prunus persica (L.) Batsch] embryos (4.0 to $8.7 \mathrm{~mm}$ long) was investigated. Maximum embryo dry weights were attained with vermiculite support, ovule perforation, and $10 \%$ sucrose in the medium. At high sucrose levels, all three tested media (Monnier, modified Murashige and Skoog, or modified Stewart and Hsu medium) performed similarly. Adding IAA and kinetin to culture media did not enhance embryo growth. Using the vermiculite support system, small embryos of early maturing peach cultivars, obtained at fruit maturity, were cultured successfully and used as maternal parents in breeding programs. Chemical name used: indole acetic acid (IAA).
\end{abstract}

Seeds from early maturing peach cultivars that have fruit development periods (FDP) of $<75$ days fail to germinate due to small embryo size (Lesley and Bonner, 1952). A peach embryo's ability to germinate is correlated with its size (Kester and Hesse, 1955). Although embryo length and fresh weight are frequently used as size measurements (Kester and Hesse, 1955; Ramming, 1990), embryo dry weight is a more reliable indicator of maturity and viability. Ramming (1990) reported that the minimum size for successful embryo culture using Smith, Bailey, and Hough (1969) medium with 3\% sucrose was 10-mmlong embryo and $60 \%$ ovule fill (embryo length $\div$ ovule length $\times 100$ ). This finding has been confirmed in our laboratory with 20 peach genotypes (unpublished data). The equivalent embryo (ovule) dry weight and percent dry weight (embryo dry weight $\div$ embryo fresh weight $\times 100)$ were $20 \mathrm{mg}(38 \mathrm{mg})$ and $9 \%$

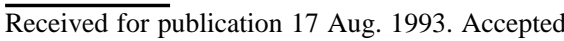
for publication 14Feb. 1994. Research supported by U.S. Dept. of Agriculture (USDA) Hatch Act Funds, Texas Agricultural Expt. Station, and the Empresa Brasileira de Pesquisa Agropecuária. Texas Agricultural Expt. Station Manuscript no. 31529. Mention of a trademark, proprietary product, or vendor does not constitute a guarantee or warranty of the product by the Texas A\&M Univ. and does not imply its approval to the exclusion of other products or vendors that may also be suitable. We thank Ralph Scorza of USDA-Agricultural Research Service, Appalachian Fruit Research Station, Kearneysville, W.Va., for supplying B611505 fruit The cost of publishing this paper was defrayed in part by the payment of page charges. Under postal regulations, this paper therefore must be hereby marked advertisement solely to indicate this fact.

${ }^{1}$ Graduate Student.

${ }^{2}$ Assistant Professor.

${ }^{3}$ Associate Professor.
(10\%), respectively. Embryos larger than these germinated more reliably (Kester and Hesse, 1955; Ramming, 1990). Germination failure precludes using early maturing peach genotypes as female parents in breeding programs. Although in ovule embryo culture has been used to promote immature $(<5 \mathrm{~mm})$ peach embryo growth (Ramming, 1990), success has been low (32\%), and improved techniques and culture media are needed. Possible alterations to enhance embryo in vitro development include adding hormones, changing the basic nutrient mixture, altering the ovule support method, and perforating the ovule.

MS (Murashige and Skoog, 1962), SH (Stewart and Hsu, 1977), and Monnier (1976) media have been used for in ovule culture of immature embryos (Monnier, 1976; Ramming, 1985; Stewart and Hsu, 1977). Ramming (1985) reported that SH was better than MS for small $(<10 \mathrm{~mm})$ peach embryo culture. In addition, Pinto et al. (1993) reported that SH and Monnier were useful for enhancing the small peach embryo growth, but the media Successful in ovule culture of small peach embryos has been reported at medium $(6 \%)$ to high $(10 \%$ to $12 \%)$ sucrose concentrations (Pinto et al., 1993; Ramming, 1985), but little is known about the interaction between the media and sucrose level. Although the exogenous growth regulators kinetin and IAA have promoted growth of some immature embryos (Raghavan, 1966; Rangan, 1984), little work has been done with peach in this regard (Ramming, 1990). Pinto et al. (1993) found that using exogenous growth regulators was not effective for peach embryo culture.

The in vitro method of ovule support affects peach embryo growth (Fernandez et al., 1991; Ramming, 1985; Stewart and Hsu, 1977). Peach embryos grow better on filter paper were not compared directly to each other. support (FPS) than when immersed in liquid medium (Ramming, 1985); however, paper supports preparations are time consuming. Recently, a vermiculite system has been described as useful (Pinto et al., 1993), but its effectiveness in encouraging embryo growth was not compared to the FPS system.

Ovule culture techniques and manipulations promote embryo development in several crops including Vitis, Cuphea, and Hordeum (Fernandez et al., 1991; Mathias et al., 1990; Ziebur and Brink, 1951). Cutting open the ovule can enhance embryo development (Fernandez et al., 1991; Mathias et al., 1990), presumably due to improved nutrient exchange between the medium and the embryo. Ovule manipulations, such as perforation, increase water and nutrient permeability, thus promoting embryo growth (Pinto et al., 1993). Our objectives were to evaluate the effects of medium formulations, ovule support methods, and ovule manipulations on the growth of small ( $<10 \mathrm{~mm}$ long), immature peach embryos.

\section{Materials and Methods}

General procedures. The parental selections studied were 'Goldprince', P51-2, and B611505. The first two selections were chosen because they were early ripening peach plants. B611505 was used because many fruit with small embryos (4 to $8.7 \mathrm{~mm}$ long) were available.

All media were prepared with double distilled water, and the $\mathrm{pH}$ levels were adjusted to $5.7 \pm 0.02$. The original MS medium was modified by adding (mg.liter ${ }^{-1}$ ) 16.2 $\mathrm{MnSO}_{4} \mathrm{H}_{2} \mathrm{O}$ and 0.5 thiamine $\mathrm{HCl}$ and eliminating inositol. The $\mathrm{SH}$ medium was modified by replacing the $\mathrm{NH}_{4} \mathrm{NO}_{3}$ with $\mathrm{NH}_{4} \mathrm{Cl}$ at 535 mg.liter ${ }^{-1}$ and increasing $\mathrm{KNO}_{3}$ by 10 -fold (5055 mg.liter ${ }^{-1}$ ). Monnier medium was prepared without modification (Monnier, 1976). Sucrose was added at 60 or $100 \mathrm{~g} \cdot \mathrm{liter}^{-1}$ for the first experiment and at 120 g.liter- 1 for the others. Dram vials $(9.4 \times 2.2 \mathrm{~cm} ; 37 \mathrm{ml})$ were used as culture vessels in all experiments. Embryos for all three experiments were cultured in darkness at $25 \pm 2 \mathrm{C}$ for 40 days. All fruit were surface-sterilized in $70 \%$ ethanol for $2 \mathrm{~min}$ and then in $20 \%(\mathrm{v} / \mathrm{v})$ commercial bleach $(1.05 \%$ sodium hypochlorite) for 5 min. The fruit were cracked and the ovules excised aseptically.

Support, media, and sucrose effects. Twelve treatments were used in a factorial design: three ovule support systems [FPS, gel-liquid support(GLS), and vermiculite support(VS)], two media (MS and SH), and two sucrose concentrations $(6 \%$ and $10 \%)$. The ovules containing small embryos $(8.7 \pm 1.7 \mathrm{~mm})$ were excised from B611505 fruit 70 days after full bloom (DAFB). Fruit were from the U.S. Dept. of Agriculture, Agricultural Research Service, Appalachian Fruit Research Station, Kearneysville, W.Va.

The FPS were prepared using Whatman filter paper no. $2(5.5 \mathrm{~cm})$ and $15 \mathrm{ml}$ of medium. The GLS were prepared by combining $10 \mathrm{~g}$ Gelrite (Scott, Carson, Calif.), $1 \mathrm{~g} \mathrm{MgCl}_{2}$, 
and 1 liter double-distilled water; dispensing $15 \mathrm{ml} / \mathrm{vial}$; autoclaving $15 \mathrm{~min}$ at $121 \mathrm{C}$; and cooling until the media solidified. Then, 0.9 $\mathrm{ml}$ sterilized liquid medium was poured on top of the solidified gel. For the VS treatment, 2.2 $\mathrm{g}(14 \mathrm{ml})$ of fine grade vermiculite and $9 \mathrm{ml}$ of medium were placed in each vial before autoclaving. The excised ovules were laid (one per vial) on top of the FPS, placed in the thin layer of liquid medium on the GLS, or inserted vertically with the micropylar end down twothirds deep into the wet VS. The lengths and fresh and dry weights of ovules and embryos were measured on a random 20-fruit sample on the day the experiment began (initial) and again for eight to 10 ovules from each treatment after 40 days in culture.

Monniervs. SH media. The second experiment compared the embryo growth of perforated and intact P51-2 peach (embryo size $4 \pm$ $1 \mathrm{~mm}$ at 65 DAFB) ovules cultured on Monnier or SH medium at three growth regulator levels (IAA at $0,0.25$, or $0.5 \mathrm{mg}$.liter ${ }^{-1}$; medium that received IAA also received kinetin at 0.01 $\left.\mathrm{mg} \cdot \mathrm{liter}^{-1}\right)$. In the third experiment, the growth of 'Goldprince' embryos $(4 \pm 0.8 \mathrm{~mm}$ at 55 DAFB) cultured on Monnier or SH medium was compared.

For the second and third experiments, the embryos were cultured in ovule on VS $(2.2 \mathrm{~g}$ fine vermiculite plus $9 \mathrm{ml}$ medium) using $12 \%$ sucrose in the medium. Before culturing, the prepared vials were autoclaved at $121 \mathrm{C}$ for 20 min. For the ovule perforation (OP) treatment, excised ovules were perforated 12 times with a tearing needle around the micropylar end without damaging the embryos inside. The lengths of 10 embryos were measured at the beginning of the experiment, and the length of seven to 10 embryos were measured after 40 days in culture.

Statistical analysis. The SAS general linear model procedure was used to analyze the data as factorial for the first and second experiments; the third experiment was analyzed as a completely randomized design. The means were separated by Duncan's multiple range test (SAS Institute, 1985).

\section{Results and Discussion}

Support, media, and sucrose effects. The embryo and ovule increases in percent dry weight were influenced more by support systems than medium or sucrose concentration. Ovule length was not affected by the treatments (data not shown). The dry weight (percent) of the GLS embryos was significantly lower $(3.3 \%$ to $6.2 \%)$ than that of embryos grown on either the VS $(10.8 \%$ to $32.7 \%)$ or FPS $(9.1 \%$ to $22.8 \%)$ systems (Tables 1 and 2 ). This result indicates that the increases in GLS embryo fresh weight were due to higher water content. The embryos from the GLS treatment were flaccid and appeared watersoaked, but those grown on the VS system were firm and white. According to BarrettLennard and Dracup (1988), an increase in air porosity in the culture medium prepared by breaking gelled medium into clumps promotes shoot growth of Trifolium subterraneum in vitro. Hence, the greater effectiveness of the VS system compared to the GLS system may have been due to higher gas diffusion from the support medium to the embryo. The GLS system had $0.9 \mathrm{ml}$ compared to $9 \mathrm{ml}$ medium in the VS system, which also may have influenced effectiveness.

The increase in dry and fresh weight of ovules and embryos on FPS was intermediate compared to those on the GLS and VS systems. Response to FPS was better than to GLS, confirming Ramming's (1985) findings that FPS is better than immersing embryos in liquid medium. The FPS system, however, was difficult to set up and generally inferior to the VS system in promoting embryo growth (dry weight, fresh weight, and length). In addition, the VS system that oriented the ovules vertically promoted uniform cotyledon growth; this growth contrasts the asymmetrical cotyledon growth from embryos cultured with the FPS and GLS systems, which oriented ovules horizontally.

Medium type and sucrose concentrations affected percent dry weight of embryos and ovules (Tables 1 and 2). Embryos cultured on
VS with SH at $6 \%$ or $10 \%$ sucrose or on MS plus $10 \%$ sucrose increased nearly two to three times more in embryo dry weight and percent embryo dry weight than those embryos cultured on GLS or FPS (Table 1). Although the dry weights of embryos on VS with either MS plus $10 \%$ sucrose or SH plus $6 \%$ or $10 \%$ sucrose were similar, those on $\mathrm{SH}$ plus $10 \%$ sucrose had the highest percent dry weights. The SH plus $6 \%$ or $10 \%$ sucrose medium with $\mathrm{VS}$ led to an average of 1.5-times higher percentage of embryo dry weight compared to the same media with FPS. An experiment comparing the effects of $10 \%$ and $12 \%$ sucrose on embryo and ovule growth (dry weight, fresh weight, and length) revealed no difference between the two (data not shown).

Ovule manipulations. P51-2 embryos were longer with OP than when left intact, regardless of medium and hormone concentrations used (Table 3). This result confirms previous work on smaller embryos (Pinto et al., 1993). Carbohydrates and other organic compounds enter the nucellus through diffusion (Murray, 1988; Yamaki and Ryugo, 1986). Working with small Cuphea embryos, Mathias et al. (1990) suggested that the seedcoat might limit this diffusion. The OP technique may have enhanced embryo growth in length by improving nutrient diffusion from the culture medium to the developing embryo or by direct tissue wounding. Embryo dry weights were not measured in this experiment because the embryos were cultured further in another experiment.

Media and hormone effects. Medium formulation had little effect on embryo growth with the selections that we tested. In the second experiment, Monnier and modified $\mathrm{SH}$ media equally promoted the growth in length of perforated 'Goldprince' and P51-2 embryos (Table 3). Exogenous hormones did not stimulate length growth of P51-2 embryos (4 $\mathrm{mm}$ long at 65 DAFB), confirming Pinto et al.'s (1993) results. Perhaps, this response was because embryos were hormone autotrophic or the hormone levels used were inappropriate.

Table 1. Ovule and embryo growth as affected by three support systems, two sucrose levels, and two media (Murashige and Skoog salts = MS or Stewart and Hsu salts $=\mathrm{SH}$ ) compared with initial noncultured controls. Cultures were maintained in darkness for 40 days.

\begin{tabular}{|c|c|c|c|c|c|c|c|c|c|}
\hline \multirow[b]{2}{*}{ Medium } & \multirow[b]{2}{*}{$\begin{array}{c}\text { Sucrose } \\
\text { concn }(\%)\end{array}$} & \multicolumn{5}{|c|}{ Embryo } & \multicolumn{3}{|c|}{ Ovule } \\
\hline & & $\begin{array}{c}\begin{array}{c}\text { Ovule support } \\
\text { system }^{2}\end{array} \\
\end{array}$ & $\begin{array}{l}\text { Length } \\
(\mathrm{mm})\end{array}$ & $\begin{array}{c}\text { Fresh wt } \\
(\mathrm{mg})\end{array}$ & $\begin{array}{c}\text { Dry wt } \\
(\mathrm{mg})\end{array}$ & $\begin{array}{c}\% \text { Dry } \\
\text { wt }^{\mathrm{y}}\end{array}$ & $\begin{array}{c}\text { Fresh wt } \\
(\mathrm{mg})\end{array}$ & $\begin{array}{c}\text { Dry wt } \\
(\mathrm{mg})\end{array}$ & $\begin{array}{c}\% \text { Dry } \\
\text { wt }\end{array}$ \\
\hline Initial $^{\mathrm{x}}$ & & & $8.7 \mathrm{~d}^{\mathrm{w}}$ & $96 \mathrm{f}$ & $8.0 \mathrm{~d}$ & $8.4 \mathrm{ef}$ & $614 b c$ & $60.0 \mathrm{ef}$ & $9.8 \mathrm{ef}$ \\
\hline \multirow[t]{6}{*}{ MS } & 6 & FPS & $11.2 \mathrm{bc}$ & $174 \mathrm{~d}-\mathrm{f}$ & $16.0 \mathrm{~cd}$ & $9.1 \mathrm{ef}$ & $528 \mathrm{~b}-\mathrm{e}$ & $64.4 \mathrm{bc}$ & $11.7 \mathrm{de}$ \\
\hline & 6 & GLS & $12.6 \mathrm{ab}$ & $296 \mathrm{a}-\mathrm{d}$ & $11.9 \mathrm{~d}$ & $3.7 \mathrm{~g}$ & $702 \mathrm{ab}$ & $35.8 \mathrm{ed}$ & $5.4 \mathrm{gh}$ \\
\hline & 6 & VS & $11.8 \mathrm{~b}$ & $235 \mathrm{~b}-\mathrm{e}$ & $25.2 \mathrm{~b}-\mathrm{d}$ & $10.8 \mathrm{e}$ & $433 \mathrm{c}-\mathrm{f}$ & $60.3 \mathrm{bc}$ & $14.0 \mathrm{~d}$ \\
\hline & 10 & FPS & $7.6 \mathrm{~d}$ & $69 \mathrm{f}$ & $11.6 \mathrm{~d}$ & $15.9 \mathrm{~cd}$ & 344 ef & $63.1 \mathrm{bc}$ & $18.7 \mathrm{c}$ \\
\hline & 10 & GLS & $12.0 \mathrm{~b}$ & $250 \mathrm{~b}-\mathrm{e}$ & $11.0 \mathrm{~d}$ & $4.2 \mathrm{~g}$ & $708 \mathrm{ab}$ & $39.0 \mathrm{de}$ & $6.0 \mathrm{gh}$ \\
\hline & 10 & VS & $12.7 \mathrm{ab}$ & $355 \mathrm{ab}$ & $63.3 \mathrm{a}$ & $19.0 \mathrm{c}$ & $573 b-d$ & $107.0 \mathrm{a}$ & $19.9 \mathrm{c}$ \\
\hline \multirow[t]{6}{*}{$\mathrm{SH}$} & 6 & FPS & $10.9 \mathrm{bc}$ & $239 \mathrm{~b}-\mathrm{e}$ & $34.8 \mathrm{~b}$ & $14.8 \mathrm{~d}$ & $414 \mathrm{~d}-\mathrm{f}$ & $69.6 \mathrm{~b}$ & $17.0 \mathrm{c}$ \\
\hline & 6 & GLS & $12.3 \mathrm{ab}$ & $304 \mathrm{a}-\mathrm{c}$ & $10.8 \mathrm{~d}$ & $3.3 \mathrm{~g}$ & $805 \mathrm{a}$ & $35.3 \mathrm{e}$ & $4.4 \mathrm{~h}$ \\
\hline & 6 & VS & $11.1 \mathrm{bc}$ & $293 \mathrm{a}-\mathrm{d}$ & $57.4 \mathrm{a}$ & $19.3 \mathrm{c}$ & $597 b-d$ & $118.4 \mathrm{a}$ & $19.8 \mathrm{c}$ \\
\hline & 10 & FPS & $9.5 \mathrm{~cd}$ & 135 ef & $32.2 \mathrm{bc}$ & $22.8 \mathrm{~b}$ & $309 \mathrm{f}$ & $73.2 \mathrm{~b}$ & $23.5 \mathrm{~b}$ \\
\hline & 10 & GLS & $14.3 \mathrm{a}$ & $402 \mathrm{a}$ & $23.0 \mathrm{~b}-\mathrm{d}$ & $6.2 \mathrm{fg}$ & $681 \mathrm{ab}$ & $50.0 \mathrm{~b}-\mathrm{d}$ & $7.5 \mathrm{fg}$ \\
\hline & 10 & VS & $11.2 \mathrm{bc}$ & $186 \mathrm{c}-\mathrm{f}$ & $59.8 \mathrm{a}$ & $32.7 \mathrm{a}$ & 354 ef & $100.6 \mathrm{a}$ & $30.5 \mathrm{a}$ \\
\hline
\end{tabular}

${ }^{\mathrm{z}} \mathrm{FPS}=$ filter paper support, GLS = gelrite support, VS = vermiculite support.

y $\%$ Dry wt $=$ dry weight as a percentage of fresh weight.

${ }^{x}$ Embryos measured the day the experiment started.

${ }^{\text {w} M e a n s ~ s e p a r a t i o n s ~ w i t h i n ~ c o l u m n s ~ b y ~ D u n c a n ' s ~ m u l t i p l e ~ r a n g e ~ t e s t ~ a t ~} P \leq 0.05$ (n $=8$ to 10$)$. 
Table 2. Analysis of variance for growth of ovules and embryos on three support systems and two media compared to initial, noncultured controls.

\begin{tabular}{|c|c|c|c|c|c|}
\hline \multirow{2}{*}{$\begin{array}{l}\text { Source of } \\
\text { variation }\end{array}$} & \multicolumn{3}{|c|}{ Embryo } & \multicolumn{2}{|c|}{ Ovule } \\
\hline & Length & Fresh wt & Dry wt & Fresh wt & Dry wt \\
\hline Ovule support (O) & $* *$ & $* *$ & $* *$ & $* *$ & $* *$ \\
\hline Media (M) & NS & NS & $* *$ & NS & $* *$ \\
\hline Sucrose level (S) & NS & NS & $* *$ & $*$ & $* *$ \\
\hline $\mathrm{O} \times \mathrm{M}$ & NS & $*$ & $* *$ & NS & $* *$ \\
\hline $\mathrm{O} \times \mathrm{S}$ & $* *$ & NS & $* *$ & NS & $* *$ \\
\hline $\mathrm{M} \times \mathrm{S}$ & NS & NS & $*$ & $*$ & $*$ \\
\hline $\mathrm{O} \times \mathrm{M} \times \mathrm{S}$ & NS & $* *$ & NS & $*$ & NS \\
\hline
\end{tabular}

Ns, *, ** Nonsignificant or significant at $P \leq 0.05$ or 0.01 , respectively.

Table 3. Final length of small peach embryos cultured in ovule as affected by media, IAA, and ovule perforation on vermiculite support.

\begin{tabular}{|c|c|c|c|c|c|c|c|}
\hline \multirow{5}{*}{$\begin{array}{l}\text { Parental } \\
\text { selection }^{y}\end{array}$} & \multirow{5}{*}{$\begin{array}{c}\text { Ovule } \\
\text { perforation }\end{array}$} & \multicolumn{6}{|c|}{ Embryo length (mm) } \\
\hline & & \multicolumn{6}{|c|}{ Medium } \\
\hline & & \multicolumn{3}{|c|}{ Monnier } & \multicolumn{3}{|c|}{$\mathrm{SH}^{\mathrm{z}}$} \\
\hline & & \multicolumn{3}{|c|}{ IAA (mg.liter $\left.{ }^{-1}\right)$} & \multicolumn{3}{|c|}{ IAA (mg•liter $\left.{ }^{-1}\right)$} \\
\hline & & 0 & 0.25 & 0.50 & 0 & 0.25 & 0.50 \\
\hline$\overline{\text { Goldprince }^{\mathrm{x}}}$ & + & $11.1 \mathrm{a}^{\mathrm{w}}$ & ---- & ---- & $11.0 \mathrm{a}$ & ---- & ---- \\
\hline P51-2 & $\begin{array}{l}+ \\
-\end{array}$ & $\begin{array}{c}11.4 \mathrm{ab} \\
6.0 \mathrm{c}\end{array}$ & $\begin{array}{l}9.8 \mathrm{~b} \\
5.3 \mathrm{c}\end{array}$ & $\begin{array}{r}13.1 \mathrm{a} \\
5.1 \mathrm{c}\end{array}$ & $\begin{array}{r}10.4 \mathrm{~b} \\
6.1 \mathrm{c}\end{array}$ & $\begin{array}{r}10.2 \mathrm{~b} \\
5.7 \mathrm{c}\end{array}$ & $\begin{array}{l}9.8 \mathrm{~b} \\
5.6 \mathrm{c}\end{array}$ \\
\hline
\end{tabular}

${ }_{\mathrm{z}}^{\mathrm{S} H}=$ modified Stewart and Hsu medium, all three treatments contained $0.01 \mathrm{mg}$ kinetin/liter and $12 \%$ sucrose.

y'Goldprince' ( $4 \pm 0.8 \mathrm{~mm})$ and P51-2 (4 $\pm 1.0 \mathrm{~mm})$ embryos were 55 and 65 days old, respectively, when cultures were initiated.

'Analysis of variance for 'Goldprince' embryo length showed medium effects were nonsignificant.

wWithin each genotype, means separation by Duncan's multiple range test at $P \leq 0.05$.

${ }^{v}$ Analysis of variance showed P51-2 embryo length growth to be nonsignificant, ovule perforation treatment significant at $P \leq 0.01$, and medium-hormone treatment and interactions nonsignificant.

The VS method improved small embryo (4 to $8.7 \mathrm{~mm}$ ) growth relative to FPS or GLS, while reducing the labor needed for embryo rescue. In general, the ovule support system and ovule manipulation techniques were more effective than media formulations for stimulating in vitro growth of immature embryos of early ripening peach cultivars. The optimum system for 'Goldprince', P51-2, and B611505 was VS support plus OP with $10 \%$ sucrose and either SH, Monnier, or MS medium. Adding IAA and kinetin to the culture media did not stimulate embryo growth.

\section{Literature Cited}

Barrett-Lennard, E.G. and M. Dracup. 1988. A porous agar medium for improving the growth of plants under sterile conditions. Plant \& Soil 108:294-298.

Fernandez, G.E., J.R. Clark, and J.N. Moore. 1991. Effect of seedcoat manipulation on the germination of stenospermocarpic grape embryos cultured in ovulo. HortScience 26:1220.

Kester, D.E. and C.O. Hesse. 1955. Embryo culture of peach varieties in relation to season of ripening. Proc. Amer. Soc. Hort. Sci. 65:265-273.

Lesley, J.W. and J. Bonner. 1952. The development of normal peach seedlings from seeds of earlymaturing varieties. Proc. Amer. Soc. Hort. Sci. 60:238-242.

Mathias, R., S. Espinosa, and G. Robbelen. 1990. A new embryo rescue procedure for interspecific hybridization. Plant Breeding 104:258261.

Monnier, M. 1976. Culture in vitro de l'embryon immature de Capsella bursa - pastoris Moench. Rev. Cytol. Biol. Veg. 39:1-120.

Murashige, T. and F. Skoog. 1962. A revised medium for rapid growth and bioassays with tobacco tissue cultures. Physiol. Plant. 15:473497.

Murray, D.R. 1988. Nutrition of angiosperm embryos. Research Studies, Taunton, England.

Pinto, A.Q.C., D.H. Byrne, and S.M.D. Rogers. 1993. Influence of ovule perforation, plant growth regulators and L-glutamine on in vitro growth of immature peach embryos. In Vitro Plant Cellular Dev. Biol. 29P:55-58.

Raghavan, V. 1966. Nutrition, growth and morphogenesis of plant embryos. Biol. Rev. 41:1-58.

Ramming, D. 1985. In ovulo embryo culture of early-maturing Prunus. HortScience 20:419_ 420.

Ramming, D. 1990. The use of embryo culture in fruit breeding. HortScience 25:393-398.

Rangan, T.S. 1984. Culture of ovules, p. 227-231. In: I.K. Vasil (ed.). Cell culture and somatic cell genetics of plants. vol. 1. Academic, Orlando, Fla.

SAS Institute. 1985. SAS user's guide: Statistics. Version 5 ed. SAS Inst., Cary, N.C.

Smith, C.A., C.H. Bailey, and L.F. Hough. 1969. Methods for germinating seeds of some fruit species with special reference to growing seedlings from immature embryos. New Jersey Agr. Expt. Sta. Bul. 823.

Stewart, J.M. and C.L. Hsu. 1977. In ovulo embryo culture and seedling development of cotton (Gossypium hirsutum L.). Planta 137:113-117.

Yamaki, S. and K. Ryugo. 1986. Peach ovules, a model for studying photosynthate unloading mechanism. HortScience 21:757. (Abstr.)

Ziebur, N.K. and R.A. Brink. 1951. The stimulative effects of Hordeum endosperms on the growth of immature plant embryos in vitro. Amer. J. Bot. 38:253-256. 